\title{
Extrauterine intrapartum treatment procedure in the unilateral advanced fetal hydrothorax case
}

\author{
Sevil Eraslan, Rauf Melekoğlu, Ebru Çelik \\ Department of Gynecology \& Obstetrics, Faculty of Medicine, Inönii University, Malatya, Turkey
}

\begin{abstract}
Objective: Congenital hydrothorax is a rare anomaly seen in one per 10,000-15,000 pregnancies. Progress of the prenatal diagnosis has enabled the practice of extrauterine intrapartum treatment (EXIT) procedure in the fetal hydrothorax management. In this report, we presented a unilateral advanced fetal hydrothorax case found on ultrasonography at third trimester and underwent EXIT procedure during delivery.

Case: No additional anomaly was observed except unilateral pleural effusion and polyhydramnios on the right in the obstetric ultrasonography of the thirty-five-year-old primigravida patient with no specific finding in medical and obstetric histories who was referred to our clinic when pleural effusion and polyhydramnios were found in fetus at 36 weeks of gestation for the first time during routine obstetric follow-up. EXIT procedure was carried out in the case where perinatologists, neonatologist and pediatric surgeon were present in a sterile way during the cesarean operation.

Conclusion: EXIT procedure is a safe treatment option in fetal hydrothorax cases since it allows placentofetal circulation during large amount of pleural effusion discharge from newborn at birth.
\end{abstract}

Keywords: EXIT procedure, hydrothorax, obstetric surgical procedures.

\section{Introduction}

Congenital hydrothorax is the fluid accumulation in pleural cavity seen in one per 10,000-15,000 pregnancies and it has many reasons such Noonan syndrome, chromosomal anomalies, immune system disease, car-

\section{Özet: Tek taraflı ileri derecede fetal hidrotoraks olgusunda ekstrauterin intrapartum tedavi prosedürü}

Amaç: Konjenital hidrotoraks, 10.000-15.000 gebelikte bir görülen nadir bir anomalidir. Prenatal tanının ilerlemesi, fetal hidrotoraks yönetiminde ekstrauterin intrapartum tedavi (EXIT) prosedürünün uygulanmasına olanak sağlamıştır. Bu makalede 3. trimesterde ultrasonografide saptanmış, doğumda EXIT işleminin uygulandığı, tek taraflı ileri derecede fetal hidrotoraks olgusu sunulmuştur.

Olgu: Otuz beş yaşında primigravid, tıbbi ve obstetrik öyküsünde herhangi bir özellik saptanmayan, rutin obstetrik takibi sırasında ilk kez gebeliğin 36. haftasında fetüste plevral efüzyon ve polihidramniyos saptanması üzerine kliniğimize yönlendirilen hastada yapılan obstetrik ultrasonografide sağda tek taraflı plevral efüzyon ve polihidramniyos dışında ek anomali izlenmedi. Sezaryen sırasında perinatolog, neonatalog ve çocuk cerrahının steril bir şekilde hazır olarak bulunduğu vakada EXIT prosedürü uygulandı.

Sonuç: EXIT prosedürü, fetal hidrotoraks olgularında, doğumda yenidoğandan büyük miktarda plevral efüzyonun boşaltıması sırasında plasentofetal sirkülasyona izin verdiği için güvenli bir tedavi seçeneğidir.

Anahtar sözcükler: EXIT prosedürü, hidrotoraks, obstetrik cerrahi girişimler.

diac failure etc. ${ }^{[1,2]}$ Primary congenital pleural effusion may be unilateral or bilateral; it is usually on the right side and in cheilosis form. ${ }^{[3]}$ While it may regress spontaneously, it has a variable prognosis reaching up to fetal or neonatal death. ${ }^{[4,5]}$ Particularly, some of the bilateral severe congenital hydrothorax cases may
Correspondence: Rauf Melekoğlu, MD. İnönü Üniversitesi Tıp Fakültesi Kadın Hastalıkları ve Doğum Anabilim Dalı, Malatya, Turkey. e-mail: rmelekoglu@gmail.com Received: November 12, 2014; Accepted: February 24, 2015

Please cite this article as: Eraslan S, Melekoğlu R, Çelik E. Extrauterine intrapartum treatment procedure in the unilateral advanced fetal hydrothorax case. Perinatal Journal 2015;23(1):60-64.

(C2015 Perinatal Medicine Foundation
Available online at: www.perinataljournal.com/20150231013 doi: $10.2399 /$ prn.15.0231013 QR (Quick Response) Code:

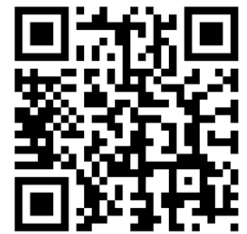


progress rapidly and may result in intrauterine death due to pulmonary hypoplasia developing as a result of long-term pressure. Antepartum treatment options have been developed depending on the increase of ultrasonography use in prenatal diagnosis. Prenatal treatment varies depending on the pleural effusion amount and the diagnosis week of gestation. ${ }^{[6]}$ If isolated pleural effusion is detected before 32 weeks of gestation, it usually has a poor prognosis and it is fatal in $55 \%$ of the cases. Mortality rate is $30 \%$ in pleural effusion cases diagnosed after 32 weeks of gestation. ${ }^{[7]}$ If hydrops fetalis accompanies pleural effusion cases, mortality rate is almost $100 \% .{ }^{[6]}$ When prenatal diagnosis is accurate and other fatal anomalies are ruled out, prenatal invasive procedure is useful, even life-saving in some bilateral cases with poor prognosis. In the presence of pleural effusion especially diagnosed at first and second trimesters, thoracic needling is not curative and thoracoamniotic shunt is preferred in such cases since recurrence rate is high. ${ }^{[8]}$

Thoracoamniotic shunt placed by using intrauterine thoracentesis or double pigtail catheter in fetal hydrothorax management is not always efficient since it depends on fetal and placental position.

If drainage and ventilation are insufficient for rapid lung expansion and alveolar gas exchange when thoracentesis is carried out after postnatal emergency intubation in pleural effusion management, permanent hypoxemic cerebral damage may occur.

Progress of the prenatal diagnosis has enabled the practice of extrauterine intrapartum treatment (EXIT) procedure in the fetal hydrothorax management. ${ }^{\left[{ }^{[]}\right.}$

EXIT is the procedure representing the operations carried out on newborn before cord flow is cut when fetal-placental unit is functional during the delivery. It is applied first in congenital diaphragmatic hernia. ${ }^{[10]}$

While the most frequent indication is external and internal airway obstructions, there are also other indications. These indications are the removal of obstructive apparatus (gripper, balloon) in the temporary tracheal obstruction, great neck masses (cervical teratoma, lymphangioma), congenital high airway obstruction syndrome (CHAOS), extracorporeal membrane oxygenization (ECMO). ${ }^{[11]}$

EXIT procedure helps to gain time for safe adaptation of newborn. ${ }^{[12]}$
In this report, we presented an unilateral advanced fetal hydrothorax case found on ultrasonography at third trimester and underwent EXIT procedure.

\section{Case Report}

Thirty-five-year-old primigravida patient with no specific finding in medical and obstetric histories was referred to our clinic when pleural effusion and polyhydramnios were found in fetus at 36 weeks of gestation for the first time during routine obstetric follow-up. In the obstetric ultrasonography of the patient whose pregnancy developed spontaneously, it was found that fetal biometric measurements were consistent with the week of gestation, there was no additional anomaly except unilateral pleural effusion and polyhydramnios on the right (Fig. 1). In the examinations to understand the reasons of fetal pleural effusion of patient whose blood type was $0 \mathrm{Rh}(+)$, maternal TORCH panel was negative and fetal echocardiography (ECO) result was normal. Biochemical examinations, gram staining, culture and karyotype analyses were done on thoracentesis fluid collected during intrauterine fetal thoracentesis. There was no reproduction in the culture analysis made on pleural fluid found to be in chylothorax characteristics according to biochemical parameter. The result of karyotype analysis was normal. The patient was provided newborn, pediatric surgery and anesthesia consultations by Perinatology Department, and cesarean operation

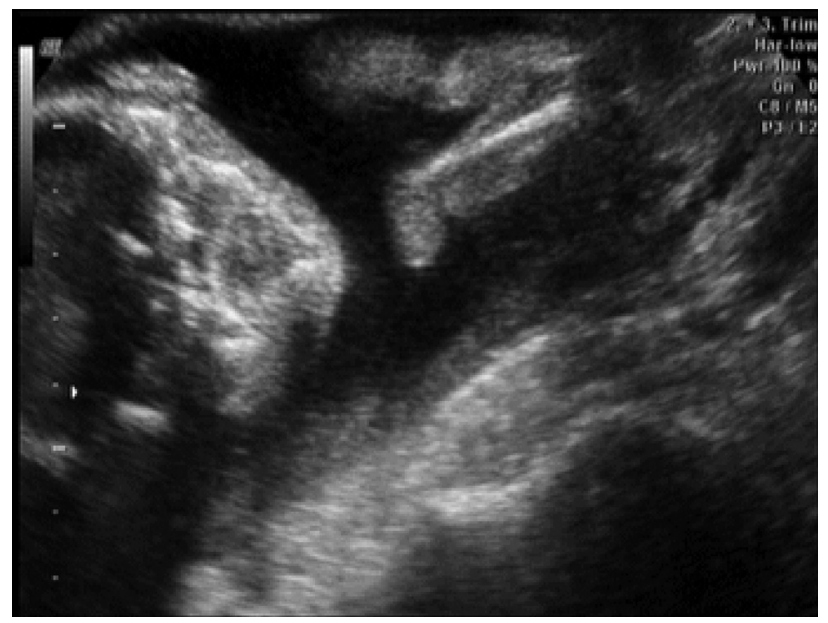

Fig. 1. The image of pleural effusion on the right side of fetus found at the 36 week of gestation via gray-scale ultrasonography. 
under elective conditions at 38 weeks of gestation and EXIT procedure were planned.

Spinal anesthesia was applied in the case where intraoperative perinatologist, neonatologist and pediatric surgeon were present in a sterile way. No drug was administered for the relaxation of uterine. By performing hysterectomy through lower segment transverse incision, $2840 \mathrm{~g}$ male baby was delivered. The newborn was placed on a sterile and flat surface on the legs of mother as maintaining uteroplacental and placentofetal circulation, not stretching the cord and on the placenta level without clamping. While obstetrician was providing maternal hemostasis, the pulse of the umbilical cord was checked during the procedure. Underwater drainage was performed by inserting tube thoracostomy into right pleural cavity via $16 \mathrm{G}$ intravenous catheter through 4th intercostal space (Fig. 2). Newborn evaluated by neonatologist during tube thoracostomy and drainage did not require intubation. During this period, about $400 \mathrm{cc}$ pleural fluid in cheilosis form was discharged. The baby, whose cord was clamped on the fourth minute of labor and who was stabilized after tube thoracostomy, was transferred to newborn intense care unit for examination, treatment and follow-up.

In the direct chest radiography during the followups in newborn intense care unit, pneumothorax was observed in the left lung and therefore thorax tube was also placed on the left side. No pathological finding was found in the examinations carried out for pleural effusion etiology. Newborn received respiratory support by nasal continuous positive airway pressure (nCPAP), and bilateral thorax tubes were removed when pleural effusion on the right and pneumothorax on the left regressed on the third day in newborn intense care unit. On the 14th day in newborn intense care unit, the baby was discharged in a healthy condition with completely regressed pleural effusion by recommending newborn clinical follow-up.

\section{Discussion}

Fetal hydrothorax may occur due to idiopathic and secondary reasons. Among the secondary reasons, there are cardiac, pulmonary and gastrointestinal malformations, infectious, hematologic and chromosomal diseases and immune hydrops. ${ }^{[13]}$

Fetal hydrothorax is a rare anomaly and its pathogenesis is not known clearly although its incidence rates increase depending on the increase of early diagnosis together with the wide use of antenatal ultrasonography. Pleural effusion case was first found by Carrol in a pregnant woman at 27 weeks of gestation. ${ }^{[14]}$ Generally, $75 \%$ of the cases are diagnosed at third trimester. In the literature, the earliest diagnosis of pleural effusion case was reported in the 13 week of gestation. ${ }^{[15]}$ Pleural effusion is usually detected by ultrasonography at third trimester and it frequently accompanies to polyhydramnios developing secondarily as a result of the external pressure of advanced pleural effusion to esophagus. ${ }^{[16]}$

The prognosis of pleural varies. Perinatal mortality rate associated with pleural effusion is about $50 \%$. Considering the clinical progress of such patients, it is seen that $22 \%$ of them regress spontaneously, $43 \%$ of them recover by treatment, and $35 \%$ of them result in fetal or neonatal death. In the absence of polyhydramnios, unilateral pleural effusion cases generally regress
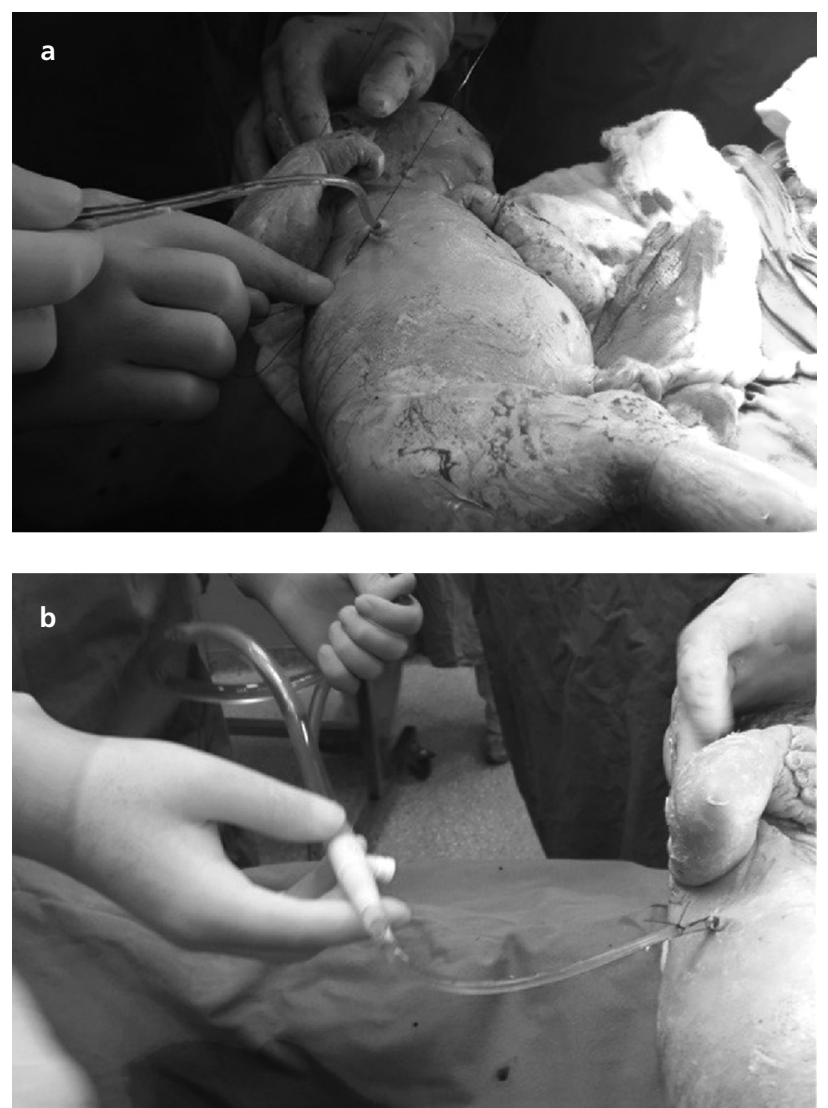

Fig. 2. EXIT procedure (a). Underwater drainage procedure by inserting thorax tube into the right pleural cavity (b). 
spontaneously. In pleural effusion cases caused by hydrops, the prognosis is poor independent from the gestational age and the presence of bilateral effusion. ${ }^{[15]}$

The initial treatment of fetal pleural effusion is the drainage with aspiration needle in company with ultrasonography. In the meantime, amniocentesis can be performed or the etiology can be investigated by collecting fetal blood sample. Reasons such as anemia and cardiac arrhythmia, which are among the causes of pleural effusion but can be treated, should be investigated. In case of the re-accumulation of pleural fluid in the follow-ups after drainage, pleuro-amniotic shunt can be considered. ${ }^{[15]}$

It was reported in the literature that EXIT procedure was first used when removing tracheal clip placed to prevent tracheal obstruction caused by severe congenital diaphragmatic hernia. ${ }^{[17]}$

EXIT is a procedure generally used in the management of extrinsic (teratomas, lymphangiomas) or intrinsic (laryngeal atresia, congenital upper airway obstruction syndrome) obstructive malformations of upper airways diagnosed during prenatal period. ${ }^{[18]}$ The widest series in the literature was reported by Bouchard et al. in 2002. Thirty-one cases applied EXIT were detailed. In their series, they did not report any case applied for pleural effusion, but they stated that they applied EXIT procedure due to mass in the neck in 13 cases and that they lost only one case during the EXIT procedure. ${ }^{[19]}$

First application of EXIT procedure in the severe advanced fetal bilateral pleural effusion case detected during prenatal period was reported by Prontera et al. in the literature. ${ }^{[20]}$

In the case reported by Prontera et al., which had pregestational diabetes and normal follow-up results until 32 weeks of gestation, severe isolated bilateral pleural effusion was found at 38 weeks of gestation, the case was applied EXIT supported bilateral thoracentesis procedure; the newborn was extubated on the 5 th day of its life, and was discharged on 25th day in a healthy condition. They emphasized that the close and efficient cooperation among anesthetist, obstetrician, neonatologist and pediatric surgeon to maintain fetoplacental circulation during EXIT procedure, and pointed out the necessity to plan the procedure in detail. ${ }^{[2]}$ In our case, we worked with the teams of anesthesia, newborn and pediatric surgery in our clinic with continuous communica- tion and cooperation both when deciding to apply EXIT procedure and planning the procedure, and we prepared plans for interventions against possible complications.

There are two significant complications which may affect EXIT procedure. First, intraoperative uterine hemorrhage may require delivering placenta swiftly; and secondly, since uterine contractions may disorder uteroplacental circulation right after the delivery, halothane administration may be required to prevent such disorder and to help the relaxation of uterine. We ensured intraoperative uterine hemostasis rapidly in our case of which we planned perinatal management and we did not need any medication reducing uterine contractions. ${ }^{[2]]}$

\section{Conclusion}

Although intrapartum thoracentesis is a preferred method in fetuses with severe pleural effusion in the last period of gestation, thoracentesis together with ultrasound may cause fetal lung injury and fetal distress induced by excessive amount of pleural fluid collection, and this procedure cannot be applied in some cases due to inappropriate fetal position. EXIT is a procedure appropriate to use in cases where intrauterine drainage is technically difficult or impossible and postpartum drainage may cause deep and extended hypoxia until pleural fluid drainage is done sufficient enough to allow lung expansion in the newborn. It is a safe treatment options as it allows placentofetal circulation during the discharge of pleural effusion in large amounts. More experience and further studies are required in order to reveal maternal and neonatal effects of applying EXIT procedure in fetal hydrothorax cases, and this procedure should be limited with viable newborns appearing only at late gestational periods today.

Conflicts of Interest: No conflicts declared.

\section{References}

1. John E. Pleural effusion in the newborn. Med J Aust 1974;1: 102-3.

2. Longaker MT, Laberge JM, Dansereau J, Langer JC, Crombleholme TM, Callen PW et al. Primary fetal hydrothorax: natural history and management. J Pediatr Surg 1989;24: 573-6.

3. Agrawal R, Aggarwal R, Kriplani A, Bhatla N. Primary Fetal Hydrothorax. Indian Pediatr 2002;39:92-5.

4. Eddleman KA, Levine AB, Chitkara U, Berkowitz RL. Reliability of pleural fluid lymphocyte counts in the antena- 
tal diagnosis of congenital chylothorax. Obstet Gynecol 1991;78(3 Pt 2):530-2.

5. Aubard Y, Derouineau I, Aubard V, Chalifour V, Preux PM. Primary fetal hydrothorax: a literature review and proposed antenatal clinical strategy. Fetal Diagn Ther 1998;13:32533.

6. Pijpers L, Reuss A, Stewart PA, Wladimiroff JW. Noninvasive management of isolated bilateral fetal hydrothorax. Am J Obstet Gynecol 1989;161:330-2.

7. Hagay Z, Reece A, Roberts A, Hobbins JC. Isolated fetal pleural effusion: a prenatal management dilemma. Obstet Gynecol 1993;81:147-52

8. Gonen R, Degani S, Shapiro I, Samberg I, Sharf M. The effect of drainage of fetal chylothorax on cardiac and blood vessel hemodynamics. J Clin Ultrasound 1993;21:265-8.

9. Kern C, Ange M, Morales, Peiry B, Pfister RE. Ex utero intrapartum treatment (EXIT), a resuscitation option for intrathoracic foetal pathologies. Swiss Med Wkly 2007;137:27985.

10. Mychaliska GB, Bealer JF, Graf JL, Rosen MA, Adzick NS, Harrison MR. Operating on placental support: the ex utero intrapartum treatment procedure. J Pediatr Surg 1997;32: 230-1.

11. MacKenzie TC, Crombleholme TM, Flake AW. The exutero intrapartum treatment. Curr Opin Pediatr 2002;14: 453-8.

12. Henry PY, Aravindan CS, Sivakumar K, Krishna HR. Extrauterine intrapartum treatment (EXIT) in bilateral primary fetal hydrothorax. Indian J Pediatr 2009;76:99-101.
13. Lange IR, Manning FA. Antenatal diagnosis of congenital pleural effusions. Am J Obstet Gynecol 1981;140:839-40.

14. Carrol B. Pulmonary hypoplasia and pleural effusions associated with fetal death in utero: ultrasonic findings. AJR Am J Roentgenol 1977;129:749-50.

15. National Institute for Health and Clinical Excellence. Insertion of pleuro-amniotic shunt to drain fetal pleural effusion (Interventional Procedure Consultation Document) [Internet]. 2006 [cited 2014 Sept 2]. Available from: www.nice.org.uk/ip333 overview

16. Mandelbrot L, Dommergues M, Aubry MC, Mussat P, Dumez Y. Reversal of fetal distress by emergency in utero decompression of hydrothorax. Am J Obstet Gynecol 1992; 167:1278-83.

17. Mychaliska GB, Bealer JF, Graf JL, Rosen MA, Adzick NS, Harrison MR. Operating on placental support: the ex utero intrapartum treatment procedure. J Pediatr Surg 1997;32: $227-31$.

18. Hirose S, Farmer DL, Lee H, Nobuhara KK, Harrison MR. The ex utero intrapartum treatment procedure: looking back at the EXIT. J Pediatr Surg 2004;39:375-80

19. Bouchard S, Johnson MP, Flake AW, Howell LJ, Myers LB, Adzick NS, et al. The EXIT procedure: experience and outcome in 31 cases. J Pediatr Surg 2002;37:418-26.

20. Prontera W, Jaeggi ET, Pfizenmaier M, Tassaux D, Pfister RE. Ex utero intrapartum treatment (EXIT) of severe fetal hydrothorax. Arch Dis Child Fetal Neonatal Ed 2002;86: F58-60. 